\title{
História
}

\section{Psicologia Escolar e Educacional: história, compromissos e perspectivas}

\author{
Mitsuko Aparecida Makino Antunes
}

Abordar a história, os compromissos e as perspectivas da Psicologia Escolar e Educacional significa tratar de três dimensões fundamentais de seu estatuto como área de conhecimento articulada a um campo de prática social. A natureza dessa relação se expressa, pelo menos, em duas dimensões: a psicologia educacional como um dos fundamentos científicos da educação e da prática pedagógica e a psicologia escolar como modalidade de atuação profissional que tem no processo de escolarização seu campo de ação, com foco na escola e nas relações que aí se estabelecem. Dada a complexidade e a multiplicidade dessas questões, seu estudo comporta um amplo espectro de focos possíveis, tornando necessária uma delimitação que implica a opção por alguns caminhos em detrimento de outros, que podem ser abordados em outras oportunidades.

Numa perspectiva mais ampla, poder-se-ia tratar a Psicologia Escolar e Educacional por algumas de suas articulações mais antigas. A Grécia Antiga, entre outras civilizações, constitui-se numa rica fonte de estudos, por sintetizar, em sua produção filosófica, a teoria do conhecimento, as idéias psicológicas e as propostas sistemáticas de educação da juventude e sua correspondente ação pedagógica. É possível, nessa perspectiva, estudar Protágoras e os sofistas, Pitágoras e a escola pitagórica, Sócrates e a maiêutica, Platão e a Academia, Aristóteles e o Liceu, entre muitos outros. Por esse mesmo foco é possível estudar o pensamento medieval, em que filosofia/teologia, educação/pedagogia e idéias psicológicas permaneceram intimamente articuladas. A modernidade trará uma complexidade que amplia muito o espectro de análise dessas relações, proporcionando um campo quase incomensurável de estudos, que estende para a contemporaneidade suas determinações e nela se faz presente. Em última análise, pode-se afirmar que a relação entre psicologia e educação, sobretudo em suas mediações com as teorias de conhecimento, é algo que acompanha a própria história do pensamento humano e constitui-se como complexo e extenso campo de estudo. Esta não é a perspectiva que será aqui tratada, mas reiterá-la é necessário para indicar a complexidade e a totalidade da qual faz parte o foco sob o qual a Psicologia Escolar e Educacional será abordada neste texto, qual seja, a Psicologia Escolar e Educacional no Brasil.

O presente texto compõe-se de uma discussão inicial sobre alguns pressupostos do estatuto da Psicologia Escolar e Educacional, uma breve história das relações entre psicologia e educação no Brasil e um ensaio sobre os compromissos e as perspectivas colocadas para a construção de uma Psicologia Escolar e Educacional comprometida socialmente com os interesses da maioria da população.

\section{Estatuto da Psicologia Escolar e Educacional: alguns pressupostos}

Essa discussão exige, antes de mais nada, a explicitação de alguns conceitos presentes nos termos da expressão Psicologia Escolar e Educacional.

Entendemos educação como prática social humanizadora, intencional, cuja finalidade é transmitir a cultura construída historicamente pela humanidade. $O$ homem não nasce humanizado, mas torna-se humano por seu pertencimento ao mundo histórico-social e pela incorporação desse mundo em si mesmo, processo este para o qual concorre a educação. A historicidade e a sociabilidade são constitutivas do ser humano; a educação é, nesse processo, determinada e determinante.

A escola pode ser considerada como uma instituição gerada pelas necessidades produzidas por sociedades que, por sua complexidade crescente, demandavam formação específica de seus membros. A escola adotou ao longo da história diversas formas, em função das necessidades a que teria que responder, tendo sido, em geral, destinada a uma parcela privilegiada da população, a quem caberia desempenhar funções específicas, articuladas aos interesses dominantes de uma dada sociedade. Essa realidade deve ser, no entanto, compreendida também a partir de suas contradições, sobretudo a concepção de escola como instância que se 
coloca hoje como uma das condições fundamentais para a democratização e o estabelecimento da plena cidadania a todos, e que, embora não seja o único, é certamente um dos fatores necessários e contingentes para a construção de uma sociedade igualitária e justa. Sob essa perspectiva, a escola, tal como nós a concebemos, tem como finalidade promover a universalização do acesso aos bens culturais produzidos pela humanidade, criando condições para a aprendizagem e para o desenvolvimento de todos os membros da sociedade.

A pedagogia pode ser entendida como fundamentação, sistematização e organização da prática educativa. A preocupação pedagógica atravessa a história, sustentando-se em diferentes concepções filosóficas, constituindo-se sob diversas bases teóricas e estabelecendo várias proposições para a ação educativa. Com o desenvolvimento das ciências a partir da modernidade, o conhecimento científico tornou-se sua principal base de sustentação.

A Psicologia Educacional ${ }^{1}$ pode ser considerada como uma sub-área da psicologia, o que pressupõe esta última como área de conhecimento. Entende-se área de conhecimento como corpus sistemático e organizado de saberes produzidos de acordo com procedimentos definidos, referentes a determinados fenômenos ou conjunto de fenômenos constituintes da realidade, fundamentado em concepções ontológicas, epistemológicas, metodológicas e éticas determinadas. Faz-se necessário, porém, considerar a diversidade de concepções, abordagens e sistemas teóricos que compõem o conhecimento, particularmente no âmbito das ciências humanas, das quais a psicologia faz parte. Assim, a psicologia da educação pode ser entendida como subárea de conhecimento, que tem como vocação a produção de saberes relativos ao fenômeno psicológico constituinte do processo educativo.

A Psicologia Escolar, diferentemente, define-se pelo âmbito profissional e refere-se a um campo de ação determinado, isto é, o processo de escolarização, tendo por objeto a escola e as relações que aí se estabelecem; fundamenta sua atuação nos conhecimentos produzidos pela psicologia da educação, por outras sub-áreas da psicologia e por outras áreas de conhecimento.

Deve-se, pois, sublinhar que psicologia educacional e psicologia escolar são intrinsecamente relacionadas, mas não são idênticas, nem podem reduzir-se uma à outra, guardando cada qual sua autonomia relativa. A primeira é uma área de conhecimento (ou sub-área) e, grosso modo,

1 Muitas expressões são utilizadas, dentre as quais: Psicologia Educacional, Psicologia da Educação, Psicologia na Educação e outras. Há implicações teóricas que subjazem à opção por uma ou outra denominação, mas que não serão aqui tratadas, dada a delimitação do presente texto. tem por finalidade produzir saberes sobre o fenômeno psicológico no processo educativo. A outra constitui-se como campo de atuação profissional, realizando intervenções no espaço escolar ou a ele relacionado, tendo como foco o fenômeno psicológico, fundamentada em saberes produzidos, não só, mas principalmente, pela sub-área da psicologia, a psicologia da educação.

\section{Relações entre Psicologia e Educação no Brasil: uma breve história}

A história da Psicologia Escolar e Educacional no Brasil pode ser identificada desde os tempos coloniais, quando preocupações com a educação e a pedagogia traziam em seu bojo elaborações sobre o fenômeno psicológico. Massimi (1986; 1990), ao estudar obras produzidas no período colonial, no âmbito da filosofia, moral, educação e medicina, entre outras, identifica temas como: aprendizagem, desenvolvimento, função da família, motivação, papel dos jogos, controle e manipulação do comportamento, formação da personalidade, educação dos indígenas e da mulher, entre outros temas que, mais tarde, tornaram-se objetos de estudo ou campos de ação da psicologia. É importante destacar que a maioria desses escritos estava comprometida com os interesses metropolitanos e expressava as mazelas de sua dominação na colônia. Entretanto, há contradições, sendo que algumas dessas obras assumiram posições que se opunham aos ideais da metrópole, como a defesa da educação feminina, entre outras. Além disso, várias obras não apenas trataram de temas que viriam a ser próprios da psicologia, mas os trataram de maneira bastante original, antecipando formulações que viriam a ser incorporadas pela psicologia do século $X X$.

No século XIX, idéias psicológicas articuladas à educação foram também produzidas no interior de outras áreas de conhecimento, embora de maneira mais institucionalizada. No campo da pedagogia, escolas normais (criadas a partir da década de 1830) foram espaços de discussão, ainda que incipientes e pouco sistemáticos, sobre a criança e seu processo educativo, incluindo temas como aprendizagem, desenvolvimento, ensino e outros. Em meados do século, essa preocupação torna-se mais sistemática e freqüente e, nos anos finais desse mesmo século, é possível perceber a incorporação de conteúdos que mais tarde viriam a ser considerados como objetos próprios da psicologia educacional, com particular interesse por temas anteriormente estudados, como aprendizagem e desenvolvimento, mas também por outros que já seriam considerados expressões da psicologia do século $X X$, como a inteligência, por exemplo. Deve-se destacar, no âmbito oficial, a Reforma Benjamin Constant, de 1890, que transformou a disciplina filosofia em psicologia e lógica, que, por desdobramento, gerou mais tarde a disciplina pedagogia e psicologia para 0 
ensino normal. Data dessa época a introdução, ainda que assistemática e pontual, do ideário escolanovista, que só mais tarde viria a se tornar hegemônico no pensamento pedagógico e teria na psicologia seu principal fundamento cientifico.

Os anos finais do século XIX e os primeiros anos do século seguinte trazem mudanças profundas na sociedade brasileira: fortalecimento do pensamento liberal; busca da "modernidade"; luta contra a hegemonia do modelo agrário-exportador, em direção ao processo de industrialização. Essas novas idéias traziam em seu bojo um novo projeto de sociedade, que exigia uma transformação radical da estrutura e da superestrutura social, para o qual seria necessário um novo homem, cabendo à educação responsabilizar-se por sua formação.

Nesse contexto, o debate sobre a educação tomou vulto, com a defesa da difusão da escolaridade para a massa da população e uma maior sistematização das idéias pedagógicas, com crescente influência dos princípios da Escola Nova. Assim, as escolas normais passaram a ser o principal centro de propagação das novas idéias, baseadas nos princípios escolanovistas, com vistas à formação dos novos professores, encarregando-se do ensino, da produção de obras e do início da preocupação com a produção de conhecimentos por meio dos então inaugurados laboratórios de psicologia, fatores estes que deram as bases para as reformas estaduais de ensino promovidas nos anos 1920 e foram por estas potencializados.

Foi nesse quadro que ocorreu, paulatinamente, a conquista de autonomia da psicologia como área especifica de conhecimento no Brasil, deixando de ser produzida no interior de outras áreas do saber, sendo reconhecida como ciência autônoma e dando as condições para que, por essa via, penetrassem os conhecimentos da psicologia que vinham sendo produzidos na Europa e nos Estados Unidos.

Assim, percebe-se uma interdependência entre psicologia e educação, sobretudo pela via da pedagogia, a partir da articulação entre saberes teóricos e prática pedagógica. Pode-se afirmar que o processo pelo qual a psicologia conquistou sua autonomia como área de saber e o incremento do debate educacional e pedagógico nas primeiras décadas do século $X X$ estão intimamente relacionados, de tal maneira que é possível afirmar que psicologia e educação são, historicamente, no Brasil, mutuamente constituintes uma da outra. Esse momento foi responsável pela consolidação da articulação entre psicologia e educação, dando as bases para a penetração e a consolidação daquilo que nos Estados Unidos e Europa já se desenvolvia sob a denominação de psicologia educacional.

O período seguinte, a partir da década de 1930, caracteriza-se pela consolidação da psicologia no Brasil e tem como base a estreita relação estabelecida entre essa área e a educação. Os campos de atuação da psicologia que se desenvolveram a partir dessa época, tornando-se campos tradicionais da profissão, como a atuação clínica e a intervenção sobre a organização do trabalho, tiveram suas raízes na educação, respectivamente pela criação dos Serviços de Orientação Infantil nas Diretorias de Educação do Rio de Janeiro e de São Paulo e da Clínica do Instituto Sedes Sapientiae, com a finalidade de atender crianças com dificuldades escolares, e pela Orientação Profissional, dentre outras ações educacionais, no campo do trabalho.

Ao mesmo tempo, o ensino formal de psicologia em cursos superiores tinha estreita articulação com a educação, pois as cátedras de psicologia estavam vinculadas primordialmente aos cursos de filosofia e de pedagogia, nestes últimos sob a denominação de psicologia educacional.

Muitos foram os trabalhos realizados pela psicologia no âmbito da educação, dentre os quais: Serviço de Psicologia Aplicada do Instituto Pedagógico da Diretoria de Ensino de São Paulo; Sociedade Pestalozzi de Minas Gerais e, posteriormente, Sociedade Pestalozzi do Brasil; "Escola para Anormais" em Recife; atividades realizadas no INEP, particularmente com a utilização de testes psicológicos; a criação das Clínicas de Orientação Infantil; o trabalho desenvolvido por Helena Antipoff na Escola de Aperfeiçoamento de Professores e na Fazenda do Rosário; Instituto de Seleção e Orientação Profissional - ISOPFGV; além dos trabalhos desenvolvidos por Ana Maria Poppovic com "crianças abandonadas" no Abrigo Social de Menores da Secretaria de Bem-Estar Social do Município de São Paulo; a fundação do Instituto de Psicologia da PUCSP, oferecendo serviços de medidas escolares, pedagogia terapêutica e orientação psicopedagógica; além das muitas instituições estritamente educacionais que desenvolviam trabalhos relacionados à Psicologia.

Pode-se dizer que a Educação continuou sendo a base para 0 desenvolvimento da psicologia, assim como esta permaneceu como principal fundamento para a educação, particularmente no âmbito pedagógico, como sustentação teórica da Didática e da Metodologia de Ensino, bases para a formação de professores. Essa tendência se expressa em experiências realizadas pela Escola Experimental da Lapa e pelos Ginásios Vocacionais em São Paulo, dentre outras inúmeras experiências, realizadas em todo o país.

Concomitantemente, o ensino nas Escolas Normais e nos Cursos de Pedagogia continuavam dando à Psicologia espaço privilegiado em seus currículos.

O desenvolvimento da pesquisa também ganha impulso, tendo como referência algumas instituições, como o Instituto de Educação do Rio de Janeiro; Escola de Aperfeiçoamento de Professores de Belo Horizonte; 
Instituto de Seleção e Orientação Profissional de Recife; Laboratório de Psicologia Educacional do Instituto de Educação (evolução do Instituto Pedagógico de São Paulo); Núcleo de Pesquisas Educacionais da Municipalidade do Rio de Janeiro; Instituto Nacional de Surdos-mudos e o Centro Brasileiro de Pesquisas Educacionais - CBPE - e seus correlatos, os Centros Regionais de Pesquisas Educacionais - CRPE; além da produção de escolas normais e universidades.

Nesse contexto, começam a se diferenciar, ainda que de forma não sistemática e formal, a psicologia educacional, como conjunto de saberes que pretende explicar e subsidiar a prática pedagógica, sendo, portanto, de domínio necessário para todos os educadores, e a psicologia escolar, como campo de atuação de profissionais da psicologia que atuariam no âmbito da escola, desempenhando uma função especifica, alicerçada na psicologia e que se caracterizou inicialmente por adotar o modelo clínico de intervenção.

Embora contradições possam ser apontadas, revelando produções teóricas e práticas afinadas com a construção de uma escola comprometida com a aprendizagem e o desenvolvimento de seus alunos, particularmente aqueles oriundos das camadas populares, o papel que a psicologia desempenhou na educação tornou-se objeto de crítica. A utilização e a interpretação indiscriminadas e aligeiradas de teorias e técnicas psicológicas, como os testes (principalmente os de nível mental e de prontidão); a responsabilização da criança e de sua família, em nome de problemas ditos de "ordem emocional", para justificar o desempenho do aluno na escola e a redução dos processos pedagógicos aos fatores de natureza psicológica colaboraram para interpretações e práticas no mínimo equivocadas, desprezando o processo educativo como totalidade multideterminada, relegando a segundo plano, ou omitindo, fatores de natureza histórica, social, cultural, política, econômica e, sobretudo, pedagógica na determinação do processo educativo.

Esse processo culmina, em 1962, com a regulamentação da profissão de psicólogo e o estabelecimento de cursos específicos para sua formação. As ações desenvolvidas no período anterior deram as bases para os campos tradicionais de atuação da psicologia: educação, clínica e trabalho.

Um fato interessante a ser mencionado é que, justamente com a regulamentação da profissão, o campo da educação, antes base principal para o desenvolvimento da psicologia no Brasil, torna-se secundário para os profissionais da área. Isso se revela não apenas no âmbito curricular, mas, sobretudo, na preferência de alunos e profissionais pelos campos da clínica e da organização do trabalho. Esse é também um dos fatores explicativos para a adoção de uma modalidade clínico-terapêutica na ação da psicologia escolar, tendo como base o modelo médico, questão que será discutida adiante.

Entretanto, as relações entre educação e psicologia vão se diferenciando. De um lado, a área da psicologia educacional, foco de interesse tanto de pedagogos como de psicólogos, e, de outro, o campo da psicologia escolar, como atributo específico do profissional da psicologia que atua no espaço escolar. O conhecimento psicológico estava incorporado à Pedagogia e à prática dos educadores e a atuação do psicólogo escolar adotava um modelo cada vez mais clínico-terapêutico, agindo fora da sala de aula, focando sua atenção na dimensão individual do educando e em seus "problemas", atendendo, sobretudo, demandas específicas da escola, que encaminhava as crianças que tinham, a seu ver, "problemas de aprendizagem" ou outras manifestações consideradas como "distúrbios" inerentes ao próprio educando.

Pode-se falar que esse período herdou do período anterior o que pode ser interpretado como hipertrofia da psicologia na educação, numa tendência reducionista, que passou, na década de 1970, a ser criticada tanto por pedagogos como por psicólogos. Criticava-se a utilização dos testes e a interpretação de seus resultados, que atribuía ao aluno a determinação de seus "problemas", desconsiderando as condições pedagógicas; o encaminhamento de alunos com deficiência que, sob a justificativa de Ihes proporcionar uma "educação especial", relegava-os a condições aligeiradas de ensino e sem solução de continuidade, reforçando estigmas e preconceitos e produzindo social e pedagogicamente a deficiência intelectual; as interpretações e ações supostamente fundamentadas na psicologia, por educadores e psicólogos, calcadas em fatores como: atraso no desenvolvimento, distúrbios de atenção, motores ou emocionais (estes em geral relacionados estritamente às condições intrínsecas da criança ou da família). Uma das conseqüências apontadas por essas críticas era a desconsideração dos determinantes de natureza social, cultural, econômica e, sobretudo, pedagógica; daí falar-se em reducionismo.

Alguns psicólogos escolares e pesquisadores da área começaram, nessa época, a elaborar uma crítica radical à Psicologia Escolar e Educacional, com base em argumentos semelhantes aos apontados por pedagogos e educadores em geral. De um lado, criticava-se a já apontada hipertrofia da psicologia na educação e o reducionismo dos fatores educacionais e pedagógicos às interpretações psicologizantes. Por outro lado, enfocando mais especificamente a prática da psicologia escolar e aprofundando a crítica a seu modo de ação, avançavam para a demonstração de que o enquadramento clínicoterapêutico baseava-se num modelo médico, estranho às determinações pedagógicas, que tendia a patologizar e 
individualizar o processo educativo, distanciando-se da compreensão efetiva dos determinantes desse processo e desconsiderando ações então denominadas preventivas, que deveriam voltar-se para as condições mais propriamente pedagógicas, de forma a atuar mais coletivamente, com base naquilo que hoje seria denominado de interdisciplinaridade, com os demais profissionais da educação e da escola. Alguns dos focos possíveis de atuação eram apontados, naquela época, em direção à formação de professores, à intervenção no âmbito das relações escola-família-comunidade, ao processo grupal estabelecido na instituição escolar, dentre outros. Particular preocupação entre psicólogos escolares incidia sobre os índices de reprovação na então 1‥ série do 1‥ Grau, que mostravam que mais da metade dos alunos ficava retida nessa série, muitas vezes na condição de alunos multirrepetentes, culminando com o abandono da escola, processo este que atingia fundamentalmente alunos oriundos das classes populares. Esse fato levou muitos profissionais da psicologia a se interessar pela alfabetização em especial e, de maneira mais ampla, pela articulação mais estreita entre os conhecimentos produzidos pela psicologia e aqueles produzidos por outras áreas de saber, principalmente a sociologia da educação, uma vez que a questão relativa à relação entre desempenho escolar e condições sócio-econômicas ganhava espaço nos debates educacionais.

Entretanto, poucos trabalhos conseguiram efetivar esse modelo de atuação, comprometido com 0 processo pedagógico, em decorrência principalmente da expectativa da escola, cristalizada na modalidade clínica de psicologia, pautada no encaminhamento do aluno para que ele fosse "curado" fora do espaço da sala de aula e depois devolvido "sem problemas", tirando da escola a responsabilidade da ação sobre a escolarização da criança. Foram, porém, esses poucos trabalhos, muitas vezes pautados na desconstrução dessas expectativas da escola, que deram as bases para a superação daquela psicologia escolar clínico-terapêutica, na direção de uma psicologia que pode ser denominada efetivamente como escolar, delimitando seu campo de atuação e criando uma modalidade de trabalho efetivamente comprometida com o cotidiano da escola em sua função essencialmente pedagógica.

Nesse sentido, a superação dessa situação exigia não somente a crítica à hipertrofia da psicologia na educação, ao reducionismo, às interpretações aligeiradas e banalizadas, às ações fundadas num modelo estranho à educação, como o modelo médico, e à culpabilização da criança e de sua família, mas também a restituição de seu núcleo de bom senso. Fazia-se necessário devolver à psicologia seu lugar no processo pedagógico.

É necessário, pois, que se considere que o processo educativo ocorre no âmbito do sujeito; assim, a dimensão psicológica não pode ser negada, mas incorporada na apreensão do fenômeno em sua totalidade, condição fundamental para a produção de conhecimento nesse campo, responsabilidade da psicologia educacional. Esta, por sua vez, deve fundamentar, naquilo que the cabe, a compreensão do fenômeno educativo e dar base para o estabelecimento de processos efetivos de intervenção, que poderiam constituir-se na matriz de atuação do psicólogo escolar.

Dessas considerações parte-se agora para um ensaio que visa discutir possibilidades e limites para a construção de uma Psicologia Escolar e Educacional, sob o foco de seus compromissos e perspectivas.

\section{Compromissos e Perspectivas para a Psicologia Escolar e Educacional}

É condição para a discussão de compromissos, assim como das perspectivas que se colocam a partir deles, a explicitação do lugar a partir do qual se fala. Compromisso implica três instâncias: aquele que se compromete (neste caso, referimo-nos à Psicologia Escolar e Educacional), aquele com quem se compromete (as classes populares) e aquilo com que se compromete (a construção de uma educação democrática). Trata-se, portanto, de discutir o compromisso da Psicologia Escolar e Educacional com a educação das classes populares, o que torna necessário expor a concepção de educação que dá base à posição aqui defendida.

A educação que aqui se afirma é uma educação rigorosa e amplamente democrática, que deve ser acessível a todos e que não transige na defesa desse princípio. É concebida como instância social responsável pela tarefa de socialização dos conhecimentos produzidos pela humanidade ao longo de sua história, criando condições para que todos possam ascender do sensocomum aos saberes fundamentados, articulados e sintéticos sobre o mundo. Educação democrática significa, portanto, democratização de saberes; saberes estes que foram historicamente privilégios - na produção e no acesso - das classes dominantes. Para que ela se realize em cada sujeito, é necessário garantir o domínio de recursos necessários para a apreensão do conhecimento, como o domínio da leitura e da escrita, da matemática e de outros recursos próprios da contemporaneidade, como informática e línguas estrangeiras. Isso, entretanto, constitui-se tão somente o ponto de partida, pois são apenas os meios necessários para a aquisição de outros conhecimentos, que devem ser considerados em todas as suas expressões, da filosofia à ciência e às artes, em permanente diálogo com a cultura própria da criança, que deve ser respeitada e considerada no processo de ensinoaprendizagem. Disso decorre uma concepção de prática pedagógica centrada nos processos de ensino e aprendizagem, cuja finalidade é propiciar o desenvolvimento pleno do educando, em todos os 
aspectos que o constitui como sujeito singular e, ao mesmo tempo, pertencente ao gênero humano.

Essa concepção de educação remete ao compromisso com a concretização de políticas públicas de educação radicalmente comprometidas com os interesses das classes populares. Isso significa garantir pleno acesso e condições de permanência de todos os educandos na escola, independentemente de suas condições, cabendo à escola transformar-se para possibilitar-lhes condições efetivas de escolarização; essa questão traduz o princípio de educação inclusiva, que incorpora não só a educação de alunos com deficiência, mas todos aqueles que, por diversos motivos, são alijados da escola e de seus bens. Para isso, faz-se necessário que se construam currículos articulados às finalidades acima expostas, superando os conhecidos "currículos mínimos", geralmente entendidos como paliativos ou educação de segunda categoria para pessoas socialmente consideradas também como tal, com especial atenção aos processos avaliativos, que têm sido um dos meios mais efetivos para a materialização da exclusão de crianças das classes populares ao direito de uma educação de boa qualidade. Esse processo depende também da gestão democrática da escola e, sobretudo, no investimento maciço na formação dos educadores.

Cabe, portanto, discutir as possibilidades e limites da Psicologia Escolar e Educacional na construção de políticas públicas de educação comprometidas socialmente com as classes populares; eis aqui a questão relativa às perspectivas colocadas para essa área de conhecimento e campo de atuação.

Disso resulta a afirmação de alguns princípios que podem ser expressos a partir das assertivas que seguem.

A educação é constituída por múltiplos determinantes, dentre os quais os fatores de ordem psicológica; portanto, a psicologia tem contribuição para a Educação.

Que seja uma psicologia capaz de compreender o processo ensino-aprendizagem e sua articulação com o desenvolvimento, fundamentada na concreticidade humana (determinações sócio-históricas), compreendida a partir das categorias totalidade, contradição, mediação e superação. Deve fornecer categorias teóricas e conceitos que permitam a compreensão dos processos psicológicos que constituem o sujeito do processo educativo e são necessários para a efetivação da ação pedagógica.

A psicologia deve assumir seu lugar como um dos fundamentos da educação e da prática pedagógica, contribuindo para a compreensão dos fatores presentes no processo educativo a partir de mediações teóricas "fortes", com garantia de estabelecimento de relação indissolúvel entre teoria e prática pedagógica cotidiana.

Esta psicologia deve propiciar a compreensão do educando a partir da perspectiva de classe e em suas condições concretas de vida, condição necessária para se construir uma prática pedagógica realmente inclusiva e transformadora.

A psicologia como um dos fundamentos do processo formativo do educador deve propiciar o reconhecimento do educador/professor como sujeito do processo educativo, traduzindo-se na necessidade de mudanças profundas das políticas de formação inicial e continuada desse protagonista fundamental da educação.

Por sua vez, a ação do psicólogo escolar deve pautarse no domínio do referencial teórico da psicologia necessário à educação, mediatizado necessariamente por conhecimentos que são próprios do campo educativo e das áreas de conhecimento correlatas. O próprio referencial teórico que aqui defendemos implica o trânsito por outros saberes (totalidade). Daí, a necessidade de superação das práticas tradicionais do psicólogo escolar, muitas vezes pautadas ainda numa perspectiva, nem sempre consciente ou assumida, de ação clínicoterapêutica.

Em outras palavras, afirmamos uma psicologia escolar comprometida radicalmente com a educação das classes populares, que supere o modelo clínico-terapêutico disfarçado e dissimulado ainda presente na representação que o psicólogo tem de sua própria ação, entendendo que a representação e, consequentemente, as expectativas que os demais profissionais da educação têm da psicologia só serão superadas pela própria prática do psicólogo escolar.

Mudanças efetivas só ocorrerão a partir do envolvimento do psicólogo com as questões concretas da educação e da prática pedagógica; é necessário superar o preconceito de não querer tornar-se "pedagogo". O psicólogo não é pedagogo, mas se quiser trabalhar com educação terá que mergulhar nessa realidade como alguém que faz parte dela, reconhecendo-se como portador de um conhecimento que pode e deve ser socializado com os demais educadores, tanto no trabalho interdisciplinar, como na formação de educadores, sobretudo professores; que detém um saber que pode contribuir com os processos sócio-institucionais da escola; tem um conhecimento específico que pode e deve reconhecer o que é próprio de sua formação profissional, e, ouso afirmar, algumas vezes inclusive de caráter clínicoterapêutico, voltado para casos individuais; possui ou pode desenvolver conhecimentos importantes para a gestão de sistemas e redes de ensino, sobretudo no âmbito de diagnósticos educacionais (avaliação institucional, docente, discente etc.) e na intervenção sobre tais resultados. 


\section{Considerações Finais}

As questões aqui expostas constituem-se em elaborações também situadas num dado momento histórico e numa dada perspectiva teórica e consequentemente política, que reflete concepções de homem, sociedade, educação, psicologia e, sobretudo, de Psicologia Escolar e Educacional circunscritas. Isso significa que esta é uma dentre muitas posições acerca dessa área de conhecimento e campo de práticas. É, portanto, importante que se estabeleça um amplo diálogo entre posições e perspectivas, que permitam o avanço dessa área de saber e o aperfeiçoamento das práticas a ela correlatas.

Entretanto, há dois aspectos que devem ser considerados nessa discussão e que remetem a aspectos cujas qualidades são muito distintas, mas que devem fazer-se invariavelmente presentes.

A primeira questão diz respeito à possibilidade de inserção do psicólogo escolar em seu campo. A Lei de Diretrizes e Bases da Educação Nacional proíbe deduzir dos $25 \%$ dos orçamentos públicos os salários de profissionais responsáveis por "atendimento médico, odontológico, psicológico e fonoaudiológico". Isso parece impedir, numa primeira leitura, a presença do psicólogo nesse campo sobre o qual incide toda nossa discussão. É preciso, no entanto, que se analise mais profundamente 0 texto da lei e os significados a ele subjacentes, cotejandoos com as questões aqui abordadas.

É compreensível e aceitável essa prescrição legal, pois, pela maneira como está colocado o serviço psicológico, deduz-se que a concepção que lhe dá base carrega a noção de atendimento clínico-terapêutico, de incidência individual e apartada das questões propriamente escolares. De um lado, a palavra utilizada é "atendimento", termo este já tradicionalmente relacionado a um modelo médico; por outro lado, e corroborando essa interpretação, o "psicológico" é acompanhado de "médico", "odontológico" e, na esteira da própria concepção de psicologia aí expressa, de "fonoaudiológico". Dada nossa concepção de Psicologia Escolar e Educacional, pode-se dizer que a psicologia a que a lei se refere não é esta que defendemos.

Essa análise demonstra que se essa atuação da psicologia não é reconhecida pela LDB como ação própria da educação, do que não discordamos, há por outro lado, uma atuação que pode ser considerada como de caráter eminentemente educacional e que tem sua prática pautada na instituição escolar e nas demandas a ela inerentes.
Com base nessa consideração, impõe-se uma discussão a respeito dessa questão, que deve subsidiar 0 esclarecimento aos órgãos direta $\mathrm{e}$ indiretamente relacionados a essa prescrição legal, além de um encaminhamento mais direto, com vistas à defesa da inserção de uma determinada prática que pode contribuir com a melhoria da educação brasileira, não como reivindicação motivada por interesses corporativistas, mas como concretização de uma luta cujo motivo primeiro é seu compromisso radical com a educação das classes populares.

A derradeira questão é de natureza ética e, sob um determinado foco, pode ser exemplificada pelo problema acima discutido. Devemos invariavelmente pautar toda e qualquer discussão sobre a Psicologia em geral e sobre a Psicologia Escolar e Educacional em especial sobre a questão ética, entendendo-a não como prescrição de normas, nem como tema da moda, mas como ética social, que se questiona e que se pergunta constantemente sobre o que fazemos, para quem, com que finalidade e a que interesses servimos.

Este é o ponto a partir do qual se deve retornar ao início dessa discussão. A história demonstra pactos entre psicologia, educação e sociedade que penderam para interesses contraditórios e opostos, na maioria das vezes em contraposição aos direitos das classes populares. Da compreensão desse processo, podemos nos lançar de maneira mais efetiva à construção de uma Psicologia Escolar e Educacional comprometida de fato com uma educação democrática, submetida aos interesses dessas classes. Este é, por sua vez, o compromisso que define e determina as perspectivas que estão postas para essa área de conhecimento e campo de atuação do psicólogo.

\section{Bibliografia}

Antunes, M. A. M. A psicologia no Brasil: leitura histórica de sua constituição. São Paulo, EDUC e Ed. Unimarco, 2003.

Massimi, M. As origens da psicologia brasileira em obras do período colonial, in: História da Psicologia. São Paulo, EDUC, Série Cadernos PUC-SP, n. 23, 1987, pp. 95-117.

História da psicologia brasileira. São Paulo, EPU,

1990.

Meira, M. E. M. e Antunes, M. A. M. Psicologia escolar: teorias críticas. São Paulo, Casa do Psicólogo, 2003.

Psicologia escolar:

práticas críticas. São Paulo, Casa do Psicólogo, 2003. 
